\title{
An Examination of Racial/Ethnic Disparities in Children's Oral Health in the United States
}

\author{
Susan A. Fisher-Owens, MD, MPH, FAAP, \\ University of California, San Francisco, School of Medicine, Department of Pediatrics \\ Inyang A. Isong, MD, MPH, \\ MGH Center for Child and Adolescent Health Policy, Boston, MA \\ Mah-J Soobader, PhD, \\ Statworks, Boston, MA \\ Stuart A. Gansky, DrPH, \\ UCSF School of Dentistry, Department of Preventive \& Restorative Dental Sciences \\ Jane A. Weintraub, DDS, MPH, \\ University of North Carolina School of Dentistry, Dean's Office \\ Larry J. Platt, MD, FACPM, and \\ UCSF School of Medicine, Philip R. Lee Institute for Health Policy Studies
}

Paul W. Newacheck, DrPH

UCSF School of Medicine, Department of Pediatrics and Philip R. Lee Institute for Health Policy Studies

\section{Abstract}

Objective-Assess the extent apparent racial/ethnic disparities in children's oral health and oral health care are explained by factors other than race/ethnicity.

Data Source-2007 National Survey of Children's Health, for children 2-17 years (N=82,020). Outcomes included parental reports of child's oral health status, receipt of preventive dental care, and delayed dental care/unmet need. Model-based survey data analysis examined racial/ethnic disparities, controlling for other child, family, and community/state (contextual) factors.

Results-Unadjusted results show large oral health disparities by race/ethnicity. Compared to non-Hispanic Whites, Hispanics and non-Hispanic Blacks were markedly more likely to be reported in only fair/poor oral health (odds ratios (ORs) [95\% confidence intervals] 4.3 [4.0-4.6], 2.2 [2.0-2.4], respectively), lack preventive care (ORs 1.9 [1.8-2.0], 1.4 [1.3-1.5]), and experience delayed care/unmet need (ORs 1.5 [1.3-1.7], 1.4 [1.3-1.5]). Adjusting for child, family, and community/state factors reduced or eliminated racial/ethnic disparities. Adjusted ORs (AORs) for Hispanics and non-Hispanic Blacks attenuated for fair/poor oral health, to 1.6 [1.51.8] and 1.2 [1.1-1.4], respectively. Adjustment eliminated disparities in each group for lacking preventive care (AORs 1.0 [0.9-1.1], 1.1 [1.1-1.2]), and in Hispanics for delayed care/unmet need (AOR 1.0). Among non-Hispanic Blacks, adjustment reversed the disparity for delayed care/ unmet need (AOR $0.6[0.6-0.7])$.

Corresponding author: Susan A. Fisher-Owens, MD, MPH, FAAP, Assistant Clinical Professor of Pediatrics, University of California, San Francisco, 1001 Potrero Avenue, MS 6E37, San Francisco, California 94110, O: 415-206-3190, F: 415-206-6900,

fisherowens@peds.ucsf.edu.

Author to whom requests for reprints should be addressed: Same

Previously presented at: Pediatric Academic Society, May 2010, Vancouver 
Conclusions-Racial/ethnic disparities in children's oral health status and access were found to be attributable largely to determinants such as socioeconomic and health insurance factors. Efforts to decrease disparities may be more efficacious if targeted at the social, economic, and other factors associated with minority racial/ethnic status, and may also have collateral positive effects on sectors of the majority population who share similar social, economic and cultural characteristics.

\section{Keywords}

children; oral health; race/ethnic disparities

\section{Introduction}

The associations between race/ethnicity and oral health outcomes are well documented(1-3) While some oral health research has considered race and ethnicity in addition to poverty and select other variables, little work has examined race and ethnicity in a broader context-one that permits assessing the effect of race/ethnicity on oral health and oral health care, when "social, economic, racial, educational, political and behavioral factors that affect ... health care issues"(4) are considered.

The purpose of this article is to examine more plainly how race/ethnicity relates to oral health care access and outcomes for children, taking into account other social determinants of health which influence, among other things, access and outcomes. Specifically, we used a large nationally representative survey to assess the independent association of race/ethnicity on oral health status and oral health care while simultaneously considering child-, familyand community-level characteristics.

\section{Methods}

\section{Conceptual Foundation}

The basis of this analysis is our conceptual model (5), detailing a multi-level approach to understanding children's oral health. This model has been used with the outcome of parentreported young children's oral health status (6), although not with a focus on racial and ethnic disparities. Thus, it is adapted accordingly here (Figure 1), to reflect at the center of the model that the focus is on oral health disparities. Some of the conceptual factors in the theoretical model were not measured in the dataset, so they were not included in the modeling.

\section{Data Source}

Data are from the 2007 National Survey of Children's Health (NSCH), conducted by CDC's National Center for Health Statistics. In brief, the NSCH was conducted from April 2007 to July 2008, using random-digit-dialing to identify households with children; NSCH sampling weights account for households without telephones or wireless-only. In each household, one child was randomly selected as the subject of an in-depth health interview. The respondent was the adult in the household most knowledgeable about the child's health; interviews were completed in English, Spanish and four Asian languages. The overall weighted response rate was $46.7 \%$. The survey methodology is described in detail elsewhere (7).

The analyses were restricted to respondents with complete data for race/ethnicity (98.1\%). Income files from CDC using multiple-imputation methodology were used in all analyses to account for the $9.3 \%$ of respondents missing income data (7). Respondents missing data for any other variable of interest were excluded from the analysis. 


\section{Dependent and Independent Variables}

For dependent variables, we selected a global measure of oral health status and two sentinel indicators of access to oral health care. Parent's report of child's oral health status was dichotomized (fair/poor vs. excellent/very good/good). Access indicators were parent's report of whether the child had at least one preventive dental visit in the past year, as a measure of access to preventive care, and parent's report of delayed dental care or unmet need in the past year, as a measure of difficulty in accessing the dental system overall. Each outcome was analyzed separately.

Independent variables, shown in Table 1, included data from the NSCH on child-, family, and neighborhood-level factors, augmented with state-level contextual data from other sources (levels determined in prior work $(5,6)$; see Table 1 footnotes for state data sources), in an effort to capture a range of the social determinants of health. Race and ethnicity were reported by parents: analytic groups were Hispanic, non-Hispanic Black, non-Hispanic White, non-Hispanic Other, and non-Hispanic Multiracial (as per NSCH). For parsimony and to reduce multicollinearity, indices were constructed where multiple questionnaire items captured similar underlying constructs; these included parental coping, social capital (as measured by perceived neighborhood support), positive neighborhood attributes, and negative neighborhood attributes (6).

\section{Analytic plan}

This analysis included children 2-17 years (sample size 82,020). Children at least two years old were selected, as their primary teeth should have started to erupt by age 1, and thus should have had dental care within the prior year (per guidelines of the American Academy of Pediatrics (8) and the American Academy of Pediatric Dentistry (9)). Preliminary analyses were conducted for two age groups, as some of the questions for younger children are different than for older children, reflecting their different activities. These two analyses did not show marked differences, and so for ease of understanding and applicability, we analyze children together as a whole, adjusting for age. Our goal was to develop a model that could be generalized to the child population and not limited to a specific age group.

Since only one child per household was sampled and households were not geocoded to the neighborhood level, the family and neighborhood levels were not distinguishable from the child level and could not be modeled statistically. Therefore, our model represents four conceptual levels (child, family, neighborhood, and state) but only two statistical levels (children within states), with external geographic variables all measured at the state level.

Our analysis first summarized the study sample, using SUDAAN (RTI, Research Triangle Park, NC) incorporating sampling weights to estimate nationally representative point prevalences for each outcome by race/ethnicity. Adjustments for the complex sample survey design were also incorporated to produce valid chi-square tests of differences between estimates. We then used a model-based approach for complex survey analysis $(10,11)$. This allowed us to estimate models with variables from individual- to state-levels, using SAS PROC GLIMMIX (SAS 9.3, SAS Institute, Cary, NC). This approach fits generalized linear mixed models with logit link to estimate adjusted odds ratios (AORs) and 95\% confidence intervals (CIs).

The modeling process entailed fitting single-domain models for the child, family, and community domains shown in Table 1 . The full model included all variables significant at the 0.05 level in any single-domain model. For each outcome, variables not significant at the 0.05 level were eliminated from the full model. Finally, we added the state-level contextual variables to each model, keeping those significant at the 0.05 level. Significant variables for each outcome are detailed in the footnotes in Table 3. Results from each imputation were 
aggregated using the SAS procedure MIANALYZE to obtain standard errors that account for variation across imputed data sets (12).

Multicollinearity was examined (13) but no instances were observed. Sample sizes were reduced in the multivariable models due to missing data on covariates by $9.5 \%$ (for fair or poor oral health), $4.0 \%$ (for delay in care or unmet need), and $7.4 \%$ (for no preventative care). The impact of bias due to missing data was evaluated by comparing to models with non-missing observations (results not shown). Results were consistent between the two approaches, indicating the results were robust to missing data.

Our goal was to assess the association of race/ethnicity while controlling for other factors. To facilitate this goal, outcomes were initially modeled with only a race/ethnicity indicator variable (Table 3, Model 1). These analyses provide an unadjusted assessment of the relationship of race/ethnicity with each outcome. Then, we tested a series of models. In Model 2, race/ethnicity and poverty status were tested together; this model estimates racial/ ethnic impact while controlling for poverty status. In Model 3, health insurance status (via two dummy variables one for public insurance and one for private), a key predictor of health care utilization was added; information on dental insurance was not available. Model 4 includes the remainder of the child-level variables as well as the family-level factors. Model 5 includes all the significant factors from Table 1. We tested interaction as described by Altman and Bland (14) to determine if the AOR in each model was significantly different from the AOR in the previous model, in those cases where CIs overlapped.

\section{Results}

\section{Unadjusted Results for Racial/Ethnic Disparities}

Only $8.8 \%$ (95\% CI: $8.1-9.4 \%$ ) of children were described by their parents as being in fair or poor oral health (Table 2). However, that report varied among racial/ethnic groups. Children of Hispanic descent had the highest percentage of reported fair or poor oral health (20.4\% [18.1-22.7\%]). This rate is markedly higher than that for non-Hispanic Whites (4.6\% [4.2-5.1\%]), non-Hispanic Blacks (9.8\% [8.5-11.2\%]), non-Hispanic Multiracial (5.3\% [3.8-6.8\%]), and non-Hispanic Other race (10.2\% [7.1-13.3\%]). Each group except non-Hispanic Multiracial children has rates of being in fair or poor oral health significantly $(\mathrm{p}<0.05)$ higher than those for non-Hispanic Whites.

Overall, 17.4\% (16.7-18.1\%) of children had not received a preventive dental care visit in the past year. Again, children receiving no care in the past year were disproportionately children of color, with highest prevalence found in Hispanic children (24.3\% [22.0-26.6\%]), as compared to non-Hispanic Whites (14.7\% [14.0-15.4\%]), non-Hispanic Blacks (18.4\% [16.7-20.1\%]), non-Hispanic Multiracial (16.9\% [13.6-20.2\%]), or non-Hispanic Other (18.1\% [15.2-21.0\%]). Both non-Hispanic Black and Hispanic children were significantly $(\mathrm{p}<0.05)$ more likely than non-Hispanic White children to lack a preventive dental visit in the prior year.

Only $3.1 \%(2.8-3.4 \%)$ of children were reported to have had a delay in care or unmet need for oral health care in the past year. There were no significant differences by race/ethnicity.

\section{Adjusted Results for Racial/Ethnic Disparities}

One of our major goals was to examine the extent to which the racial/ethnic disparities shown in Table 2 are attributable to other factors included in our conceptual model. We assessed the independent association of race/ethnicity on oral health outcomes using four multivariable models (Table 3, Models 2-5). For simplicity of presentation, we only present results for Hispanics and non-Hispanic Blacks, as these were the two racial/ethnic groups 
that showed the greatest disparities in Table 2 relative to non-Hispanic Whites (however, non-Hispanic Multiracial and non-Hispanic White children were included in the multivariable models).

In the first section of Table 3, we present the bivariable results (Model 1) for race/ethnicity for the three outcomes shown above in Table 2, but here in the form of unadjusted ORs with non-Hispanic White as the reference group. In the first multivariable model (Model 2), we examine race/ethnicity, adjusted for poverty status. These results, shown in the second group of columns in Table 3, demonstrate that the effect size of race/ethnicity, as indicated by the adjusted odds ratios, attenuates when poverty status is simultaneously considered. For instance, the unadjusted OR for having fair/poor oral health for Hispanics as compared to non-Hispanic Whites was 4.3 (3.9-4.6), but that decreased by almost half (2.6 [2.4-2.8; $\mathrm{p}<0.05])$ after adjusting for poverty status. For non-Hispanic Blacks, the initial OR was not quite as high (2.2 [2.0-2.4]), but adjusting for poverty status also attenuated the AOR by almost half to $1.4(1.3-1.6 ; \mathrm{p}<0.05)$. When additional factors are included in the model, the effect sizes for race/ethnicity further attenuated. Adding health insurance in Model 3 slightly decreased race/ethnicity disparities, to AORs $2.4(2.2-2.6)$ for non-Hispanic Blacks and to $1.3(1.2-1.5)$ for Hispanics but the changes between models were not significantly different. With all the individual- and family-level factors (Model 4), the AORs decreased further, although more for Hispanics than non-Hispanic Blacks, to $1.7(1.5-1.9 ; \mathrm{p}<0.001)$ and 1.2 (1.1-1.4, NS) respectively. In the full model, adjusting for all significant child-, family- and community-level variables from Table 1, the apparent disparity seen by race/ethnicity from the unadjusted model was markedly reduced, down to AORs of 1.6 (1.5-1.8) for Hispanics and $1.2(1.1-1.4)$ for non-Hispanic Blacks. These estimates were not significantly different from those for Model 4.

A similar pattern of attenuation in racial/ethnic disparities is shown for not having a preventive dental care visit in the prior year, but with more marked results. In the unadjusted analysis (Model 1), Hispanic children had almost twice the odds (1.9 [1.8-2.0; $<<0.001])$ of non-Hispanic White children for not having a preventive dental visit in the past year; nonHispanic Black children had a less dramatic but still significantly higher OR versus nonHispanic Whites, at $1.4(1.3-1.5 ; \mathrm{p}<0.001)$. However, as additional child-, family- and community-level variables were added, AORs for Hispanics decreased: with added factors in Models 2, 3, and 4, each subsequent model showed a statistically significant decrease in the AOR as compared to the previous model. Thus, each model explains more of the apparent racial/ethnic difference than the previous one. For non-Hispanic Blacks, even just including income (Model 2) was sufficient to eliminate the AOR differences from nonHispanic Whites (to 1.0 [1.0-1.1]; $\mathrm{p}<0.001$ ). For the Hispanic children, the AOR of having no preventive dental visits was no different compared to their non-Hispanic White counterparts by Model 4.

This pattern of attenuation of disparities is repeated again with our third outcome: parent's report of delayed dental care or unmet oral health need in the past year. On an unadjusted basis (Model 1), Hispanics and non-Hispanic Blacks had higher odds of delayed care or unmet needs than non-Hispanic Whites (1.5 [1.3-1.7] and 1.4 [1.2-1.6], respectively; both $\mathrm{p}<0.05$ ), but these disparities attenuated as additional factors were included in the model. Specifically, a decrement was seen with adjustment for income (Model 2), at which point there is no difference from non-Hispanic Whites $(0.9$ [0.8-1.0 for Hispanics and 0.9 (0.81.1) for non-Hispanic Blacks). In the full model, neither Hispanics nor non-Hispanic Blacks experienced an elevated risk of having not received preventive care; in fact, when all variables are included in the full model, non-Hispanic Black children were significantly less likely than non-Hispanic Whites to report delayed dental care or unmet oral health needs during the past year (AOR 0.6 [0.6-0.7]; $\mathrm{p}<0.05$ ). 


\section{Discussion}

The medical literature contains myriad studies showing poverty and other factors in part explain the impact of race on outcomes, such as cancer incidence $(15,16)$, childhood asthma $(17)$, and overall mortality $(18,19)$. Moreover, Kaufman and colleagues describe in detail how confounding can "bias interpretation of data toward the conclusion of independent racial/ethnic group effects”(20).

Similar findings have been shown for adults' oral health $(21,22)$. In children's oral health, $\mathrm{Yu}$ and colleagues demonstrated a diminution of the effect of race/ethnicity on receipt of preventive dental care when limited other factors were considered (23); Dietrich and colleagues saw a similar decrease in the odds ratios of disparities in fair or poor oral health with inclusion of six adjustment factors (24). Our study builds on their work by considering additional outcomes, a much larger set of child, family, community and contextual factors which represent social determinants of health and economic, racial, educational, political and behavioral factors; it also uses multiple models to show the progression of impact.

Our findings indicate that racial/ethnic disparities in children's oral health care and oral health status, while clearly present, are primarily attributed to other factors associated with race/ethnicity. One of the main contributions of our study was to see the additional impact of incorporating a broader set of individual, family, and neighborhood/state factors in the analysis of racial/ethnic disparities. We found that no single factor accounts for the observed race/ethnic disparities in oral health outcomes; rather, it is the combination of race/ethnicity, family income, and insurance which accounts for the majority of the apparent race/ethnic difference, with additional explanation derived from incorporating other individual, family, and neighborhood/state factors.

Thus, to a large degree, racial/ethnic disparities in oral health care and oral health status are not intrinsically about race or ethnicity, although of course there are components that do relate directly to appearances of race/ethnicity, such as discrimination or reduced opportunities. The most important of these factors appears to be socioeconomic status, here represented by family income in relation to the federal poverty level, but we found that other factors contributed to further attenuation of racial/ethnic disparities.

Many of the external factors we examined are mutable, whereas race/ethnicity is not. Innovative interventions that focus on these external factors may have a reasonable chance for success in reducing children's oral health disparities. These approaches could include community-based interventions and engagement (both specific to oral health as well as general health), health promotion and prevention initiatives, integration of oral health with other health activities, and other approaches which address the child's context, through education as well as policy at the local, state, and national levels.

Contextual changes can have wide-ranging impact: targeted interventions aimed at the factors that underlie racial and ethnic disparities (coined "the common risk factor approach" by Sheiham and Watt (25)) can positively impact a broad range of health issues beyond solely oral health (26). For instance, interventions directed at both parent and child, which improve access to healthy foods and health-promoting activities (such as exercise), can also decrease obesity and diabetes $(27,28)$; programs promoting personal, family, and broader contextual characteristics can reduce drug use in adolescents $(29,30)$ and improve oral health overall (6), just as these characteristics were found in our work to be associated with less racial/ethnic disparity. Similar "downstream" beneficial effects may accrue from interventions targeted at factors underlying racial/ethnic differences in oral health, interventions which could positively affect other health conditions as well by addressing social determinants of health. 
While valuable because the breadth and depth that the NSCH offers, there are limitations as with any cross-sectional survey data. The validity of survey results depends on low sampling and nonsampling errors; NSCH employs several methods to reduce such errors (7). With cross-sectional data, one cannot infer causality. Hence, our results should be viewed as correlative and provisional. In addition, there are factors in our conceptual model which were not included in our empirical analysis, either because they were not available (such as dental insurance) or for concerns of over-specifying the models; even when including as many factors as we did, there may still be other factors which would add to understanding children's oral health disparities, such as literacy or health financing.

It is perhaps surprising that little difference was seen in delayed care or unmet need. We attribute this to the fact that these questions were asked combined, when we would expect there to be differences in the way each question would be answered. There may also be cultural, socioeconomic and age differences in when an oral health issue is perceived to be a problem for which care has been delayed or there is an unmet need (for instance, a broken or missing tooth in a 2 year old may be seen as less of a problem than one in a 12 year old). The modest differences in this outcome disappear, or reverse in the case of blacks, when other variables are considered.

That our oral health status dependent variable is a subjective measure of parent's report of child's status, which might be subject to bias, merits additional discussion. While survey subjects did not have an objective exam, data support the correlation of this subjective measure with medical and mental health (31-33). Studies have shown that general health and oral health are correlated; in particular, perceived medical health can predict selfreported oral health status (34). Further, parent's subjective assessment of their children's oral health correlates with objective dental findings (35-37).

There may be further question of variation in self-report by race/ethnicity or other characteristics. In adults answering self-report questions in Spanish, there was a higher rate of fair/poor response than would be expected if they answered in English (38); this has been seen in other studies with adults, although attenuated with cultural and contextual factors (39-41). This may in part stem from translating the word "fair" in English to "regular" in Spanish. In a study done of parental assessment of preschool children's oral health, differences by race/ethnicity found in bivariable analysis lost their statistical significance after regression analysis controlled for other factors (35). In adolescents, parental report is somewhat less reliable; Weyant et al did find parents of black adolescents had increased odds of reporting their child to have fair/poor oral health (42). Of note, given that there are differences in oral health by race/ethnicity, parents' perception of their own oral health as poor was significantly related to perception of their child's oral health as poor (43). There are other factors by which parental self-report varies, such as marital status (44); this was accounted for in our model, at the family level.

\section{Conclusion}

Oral health disparities by race and ethnicity are apparent but not explained in past descriptive analyses. In a more thorough, analytical approach, when child-, family-, community-and state-level factors are considered, racial/ethnic disparities diminish considerably or even reverse. This analysis demonstrates racial/ethnic disparities in children's oral health status and access are attributable largely to child, family, community, and state factors associated with race/ethnicity, rather than to something intrinsic to race/ ethnicity. It also shows the additive value of including a more comprehensive set of variables from individual- to state-level, in the analysis of disparities. Incorporating these factors in future research can help to elucidate pathways to more effectively target and 
reduce racial and ethnic disparities in oral health and health care outcomes. Moreover, future analyses could look at these factors using structural equation modeling to try to tease out direct and indirect effects. It is not until the role of mutable socio-cultural factors influence on health is fully recognized that the field will be able to design more holistic interventions that truly improve the health of the most vulnerable racial and ethnic groups. Based on our analysis, addressing the disadvantaged circumstances experienced by racial and ethnic minority children, their families, and communities will foster the goal of eliminating children's oral health disparities.

\section{Acknowledgments}

Grant number US DHHS NIH R21 DEO18523, Lena Libatique for her outstanding support, and anonymous reviewers for their helpful comments.

\section{Abbreviations}

FPL Federal Poverty Level

NSCH National Survey of Children's Health

NH non-Hispanic

OR odds ratio

AOR adjusted odds ratio

CI confidence intervals

\section{References}

1. Beltran-Aguilar ED, Barker LK, Canto MT, Dye BA, Gooch BF, Griffin SO, et al. Surveillance for dental caries, dental sealants, tooth retention, edentulism, and enamel fluorosis--United States, 1988-1994 and 1999-2002. MMWR Surveillance Summaries. 2005 Aug 26; 54(3):1-43.

2. Dye BA, Tan S, Smith V, Lewis BG, Barker LK, Thornton-Evans G, et al. Trends in oral health status: United States, 1988-1994 and 1999-2004. Vital Health Stat 11. 2007 Apr.(248):1-92. [PubMed: 17633507]

3. Edelstein BL. Disparities in oral health and access to care: findings of national surveys. Ambul Pediatr. 2002 Mar-Apr;2(2 Suppl):141-7. [PubMed: 11950385]

4. Milgrom P, Garcia RI, Ismail A, Katz RV, Weintraub JA. Improving America's access to care: The National Institute of Dental and Craniofacial Research addresses oral health disparities. Journal of the American Dental Association. 2004; 135(10):1389-96. [PubMed: 15551979]

5. Fisher-Owens SA, Gansky SA, Platt LJ, Weintraub JA, Soobader M, Bramlett MD, et al. Influences on Children's Oral Health: A Conceptual Model. Pediatrics. 2007; 120:e510-e20. [PubMed: 17766495]

6. Bramlett MD, Fisher-Owens SA, Weintraub JA, Gansky SA, Soobader M, Platt LJ, et al. Assessing a Multilevel Model of Young Children's Oral Health with National Survey Data. Community Dent Oral Epidemiol. 2010 Mar 29.

7. Blumberg SJ, Foster EB, Frasier AM, Satorius J, Skalland BJ, Nysse-Carris KL, et al. Design and Operation of the National Survey of Children's Health, 2007. Vital and Health Statistics. 2009; 1:109.

8. Section on Pediatric Dentistry and Oral Health. Preventive Oral Health Intervention for Pediatricians. Pediatrics. 2008 Dec 1; 122(6):1387-94. [PubMed: 19015205]

9. American Academy of Pediatric Dentistry. Guideline on periodicity of examination, preventive dental services, anticipatory guidance/counseling, and oral treatment for infants, children, and adolescents. Pediatr Dent. 2008-2009; 30(7 Suppl):112-8.

10. Graubard BI, Korn EL. Modelling the sampling design in the analysis of health surveys. Stat Methods Med Res. 1996; 5(3):263-81. [PubMed: 8931196] 
11. Särndal, CE.; Swensson, B.; Wretman, J. Model Assisted Survey Sampling. New York: Springer; 1992.

12. Yuan, YC. SUGI Proceedings. SAS Institute Inc; 2000. Multiple Imputation for Missing Values: Concepts and New Development.

13. Allison, P. Logistic regression using the SAS system: Theory and application. Cary, North Carolina: SAS Institute; 1999.

14. Altman DG, Bland JM. Interaction revisited: the difference between two estimates. BMJ. 2003 Jan 25.326(7382):219. [PubMed: 12543843]

15. Krieger N. Social class and the black/white crossover in the age-specific incidence of breast cancer: a study linking census derived data to population-based registry records. Am J Epidemiol. 1990 May 1; 131(5):804-14. [PubMed: 2321624]

16. Baquet CR, Horm JW, Gibbs T, Greenwald P. Socioeconomic factors and cancer incidence among blacks and whites. J Natl Cancer Inst. 1991 Apr 17; 83(8):551-7. [PubMed: 2005640]

17. Smith LA, Hatcher-Ross JL, Wertheimer R, Kahn RS. Rethinking race/ethnicity, income, and childhood asthma: racial/ethnic disparities concentrated among the very poor. Public Health Rep. 2005 Mar-Apr;120(2):109-16. [PubMed: 15842111]

18. Rogers RG. Living and dying in the U.S.A.: sociodemographic determinants of death among blacks and whites. Demography. 1992 May; 29(2):287-303. [PubMed: 1607053]

19. Subramanian SV, Chen JT, Rehkopf DH, Waterman PD, Krieger N. Racial Disparities in Context: A Multilevel Analysis of Neighborhood Variations in Poverty and Excess Mortality Among Black Populations in Massachusetts. Am J Public Health. 2005 Feb 1; 95(2):260-5. [PubMed: 15671462]

20. Kaufman JS, Cooper RS, McGee DL. Socioeconomic status and health in blacks and whites: the problem of residual confounding and the resiliency of race. Epidemiology. 1997 Nov; 8(6):621-8. [PubMed: 9345660]

21. Hudson K, Stockard J, Ramberg Z. The Impact of Socioeconomic Status and Race-Ethnicity on Dental Health. Sociological Perspectives. 2007; 50(1):7-25.

22. Reid BC, Hyman JJ, Macek MD. Race/ethnicity and untreated dental caries: the impact of material and behavioral factors. Community Dent Oral Epidemiol. 2004 Oct; 32(5):329-36. [PubMed: 15341617]

23. Yu SM, Bellamy HA, Kogan MD, Dunbar JL, Schwalberg RH, Schuster MA. Factors that influence receipt of recommended preventive pediatric health and dental care. Pediatrics. 2002 Dec 1.110(6):e73. [PubMed: 12456940]

24. Dietrich T, Culler C, Garcia RI, Henshaw MM. Racial and ethnic disparities in children's oral health: the National Survey of Children's Health. J Am Dent Assoc. 2008 Nov; 139(11):1507-17. [PubMed: 18978389]

25. Sheiham A, Watt RG. The common risk factor approach: a rational basis for promoting oral health. Community Dentistry and Oral Epidemiology. 2000; 28(6):399. [PubMed: 11106011]

26. World Health Organization (WHO). WHO Technical Report Series. Report of the joint WHO/FAO expert consultation NT. Geneva: WHO; 2003. Diet Nutrition and the Prevention of Chronic Diseases.

27. Oude Luttikhuis H, Baur L, Jansen H, Shrewsbury VA, O’Malley C, Stolk RP, et al. Interventions for treating obesity in children. Cochrane Database Syst Rev. 2009; (1):CD001872. [PubMed: 19160202]

28. Lovasi GS, Hutson MA, Guerra M, Neckerman KM. Built Environments and Obesity in Disadvantaged Populations. Epidemiol Rev. 2009 Nov 1; 31(1):7-20. [PubMed: 19589839]

29. Foxcroft DR, Ireland D, Lister-Sharp DJ, Lowe G, Breen R. Primary prevention for alcohol misuse in young people. Cochrane Database Syst Rev. 2002; 3:CD003024. [PubMed: 12137668]

30. Hawkins JD, Catalano RF, Miller JY. Risk and protective factors for alcohol and other drug problems in adolescence and early adulthood: Implications for substance abuse prevention. Psychological Bulletin. 1992; 112(1):64-105. [PubMed: 1529040]

31. Minkovitz CS, O'Campo PJ, Chen YH, Grason HA. Associations between maternal and child health status and patterns of medical care use. Ambul Pediatr. 2002 Mar-Apr;2(2):85-92.

[PubMed: 11926838] 
32. Monette S, Seguin L, Gauvin L, Nikiema B. Validation of a measure of maternal perception of the child's health status. Child Care Health Dev. 2007 Jul; 33(4):472-81. [PubMed: 17584404]

33. Pless CE, Pless IB. How well they remember. The accuracy of parent reports. Arch Pediatr Adolesc Med. 1995; 149(5):553-8. [PubMed: 7735412]

34. Atchison KA, Gift HC. Perceived oral health in a diverse sample. Advances in Dental Research. 1997 May; 11(2):272-80. [PubMed: 9549993]

35. Talekar BS, Rozier RG, Slade GD, Ennett ST. Parental perceptions of their preschool-aged children's oral health. Journal of the American Dental Association. 2005; 136(3):364-72. [PubMed: 15819352]

36. Gansky SA, Cheng N, Pollick HF. Predicting early childhood caries with individual, family and neighborhood factors. J Dent Res. 2005 Mar 9.84(Spec Iss A):\#0012.

37. US Department of Health and Human Services. Oral Health in America: A Report of the Surgeon General. Rockville, MD: US DHHS, NIDCR, NIH; 2000.

38. Viruell-Fuentes EA, Morenoff JD, Williams DR, House JS. Language of interview, self-rated health, and the other Latino health puzzle. Am J Public Health. 2011 Jul; 101(7):1306-13. [PubMed: 21164101]

39. Shetterly SM, Baxter J, Mason LD, Hamman RF. Self-rated health among Hispanic vs nonHispanic white adults: the San Luis Valley Health and Aging Study. Am J Public Health. 1996 Dec; 86(12):1798-801. [PubMed: 9003141]

40. Bzostek S, Goldman N, Pebley A. Why do Hispanics in the USA report poor health? Soc Sci Med. 2007 Sep; 65(5):990-1003. [PubMed: 17574713]

41. Kandula NR, Lauderdale DS, Baker DW. Differences in Self-Reported Health Among Asians, Latinos, and Non-Hispanic Whites: The Role of Language and Nativity. Annals of Epidemiology. 2007; 17(3):191-8. [PubMed: 17320786]

42. Weyant RJ, Manz M, Corby P, Rustveld L, Close J. Factors associated with parents' and adolescents' perceptions of oral health and need for dental treatment. Community Dent Oral Epidemiol. 2007; 35:321-330. [PubMed: 17822480]

43. Sohn W, Taichman LS, Ismail AI, Reisine S. Caregiver's perception of child's oral health status among low-income African Americans. Pediatr Dent. 2008 Nov-Dec;30(6):480-7. [PubMed: 19186773]

44. Angel R, Worobey JL. Single motherhood and children's health. J Health Soc Behav. 1988 Mar; 29(1):38-52. [PubMed: 3367028] 


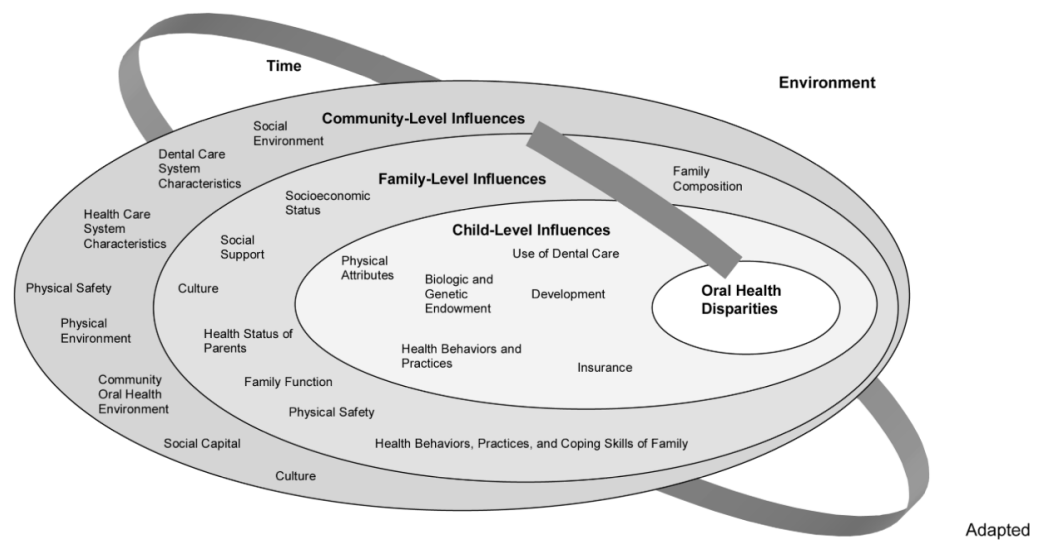

Figure 1.

Conceptual Model to Understand Oral Health Disparities (Adapted from Pediatrics (5)) [figured changed to black and white per editor's suggestion]

Adapted from Pediatrics, Vol. 120(3), Page e512, Copyright (c) 2007 by the American Academy of Pediatrics. 
Table 1

Child-, Family-, and Community-Level Influences on Children's Oral Health Disparities

\begin{tabular}{|c|c|c|}
\hline Child-Level Domains & Family-Level Domains & $\begin{array}{l}\text { Community-Level Domains (Neighborhood or } \\
\text { State) }\end{array}$ \\
\hline $\begin{array}{l}\frac{\text { Physical Attributes }}{\text { Race/ethnicity }} \\
\text { Sex } \\
\frac{\text { Biologic/Genetic Endowment }}{\text { Birth order }} \\
\frac{\text { Development }}{\text { Age }} \\
\frac{\text { Health Behaviors \& Practices }}{\text { Special health care needs }} \\
\text { Medical Home } \\
\text { Receipt of preventive medical care in } \\
\text { the past year } \\
\text { Medical Insurance } \\
\text { Insurance status (public, private, none) } \\
\text { Use of Dental Care } \\
\text { Dental visit in last year } \\
\text { Receipt of preventive dental care in the } \\
\text { past year) }\end{array}$ & $\begin{array}{l}\frac{\text { Family Composition }}{\text { Family structure }} \\
\text { Household size } \\
\text { Socioeconomic Status } \\
\text { Highest education in household } \\
\text { Family poverty status } \\
\text { Health Status of Parents } \\
\text { Physical health of parents } \\
\text { Mental health of parents } \\
\text { Use of tobacco products } \\
\frac{\text { Health Behaviors, Practices \& Coping }}{\text { Skills of Family }} \\
\text { Parental exercise patterns } \\
\text { Parental coping with child raising } \\
\text { Culture } \\
\text { Language spoken at home }\end{array}$ & 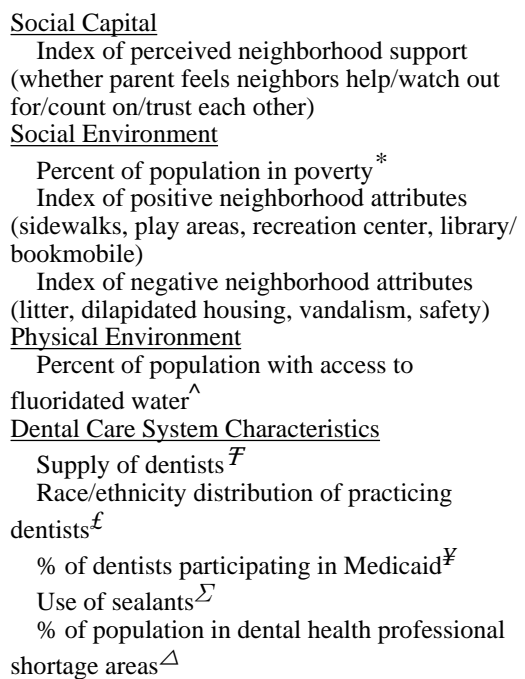 \\
\hline
\end{tabular}

US Census. State and County QuickFacts. http://quickfacts.census.gov/qfd/index.html, 2006

CDC. National Oral Health Surveillance System. http://www2.cdc.gov/nohss/ListV.asp?qkey=3. Accessed March 17, 2010; CDC MMWR CDC. Populations Receiving Optimally Fluoridated Public Drinking Water --- United States, 2000. MMWR. February 22, 2002/51(07);144-7.

${ }^{F}$ US Department of Health \& Human Services--Health Resources and Services Administration. Financing Dental Education: Public Policy Interests, Issues and Strategic Considerations. http://bhpr.hrsa.gov/healthworkforce/reports/dental/c3.htm

$£$

. Assessment of the Dental Public Health Infrastructure in the United States, 2004 http//www nidcr. nih gov/NR/rdonlyres/

E7AEAF78-667F-43D8-BA48-A981A01CD437/0/US_Dental_Public_Health_Infrastructure_8_2004.pdf. Accessed March 7, 2008.

$¥$ CDC- National Center for Chronic Disease Prevention and Health Promotion. Synopses of State and Territorial Dental Public Health Programs Synopses by State. 4/4/2006; http://apps.nccd.cdc.gov/synopses/StateDataV.asp?StateID=AL\&Year=2005, 2006.

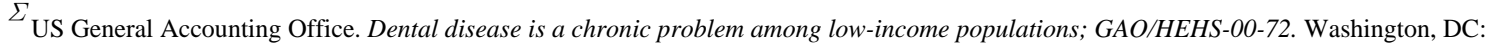
General Accounting Office; 2000.

${ }^{\triangle}$ US Department of Health \& Human Services--Health Resources and Services Administration. Dental Care Health Professional Shortage Areas. http://datawarehouse.hrsa.gov/. Accessed March 6, 2008. 
Table 2

Prevalence of Oral Health Outcomes by Race/Ethnicity

\begin{tabular}{|l|c|c|c|}
\hline Race/Ethnicity & $\begin{array}{c}\text { Fair or Poor Oral Health Status } \\
\mathbf{N = 8 0 , 5 6 6} \text { (n, \% [CIs]) }\end{array}$ & $\begin{array}{c}\text { No Preventive Dental Visits in Past } \\
\text { Year N=80,343 (n, \% [CIs]) }\end{array}$ & $\begin{array}{c}\text { Delayed Care or Unmet Dental } \\
\text { Care Need in Past Year N= 80,532 } \\
(\mathbf{n}, \mathbf{\%} \text { [CIs]) }\end{array}$ \\
\hline Overall & $\begin{array}{c}4,822 \\
{[8.1-9.4]}\end{array}$ & 11,652 & 2,041 \\
$17.4[16.7-18.1]$ & $3.1[2.8-3.4]$ \\
\hline Hispanic & 1,505 & 2,153 & 326 \\
& $20.4^{*}[18.1-22.7]$ & $24.3^{*}[22.0-26.6]$ & $3.5[2.6-4.4]$ \\
\hline NH Black & 664 & 1,308 & 238 \\
& $9.8^{*}[8.5-11.2]$ & $18.4^{*}[16.7-20.1]$ & $3.4[2.5-4.3]$ \\
\hline NH Multiracial & 181 & 573 & 148 \\
& $5.3[3.8-6.8]$ & $16.9[13.6-20.2])$ & $4.4[2.9-5.9]$ \\
\hline NH Other & 287 & 607 & 107 \\
& $10.2^{*}[7.1-13.3]$ & $18.1[15.2-21.0]$ & $2.0[1.4-2.6]$ \\
\hline NH White & 2,185 & 7,011 & 1,222 \\
& $4.6[4.2-5.2]$ & $14.7[14.0-15.4]$ & $2.8[2.4-3.2]$ \\
\hline
\end{tabular}

CI: confidence interval; NH: Non-Hispanic

$*$

p $\leq 0.05$ vs NH White 


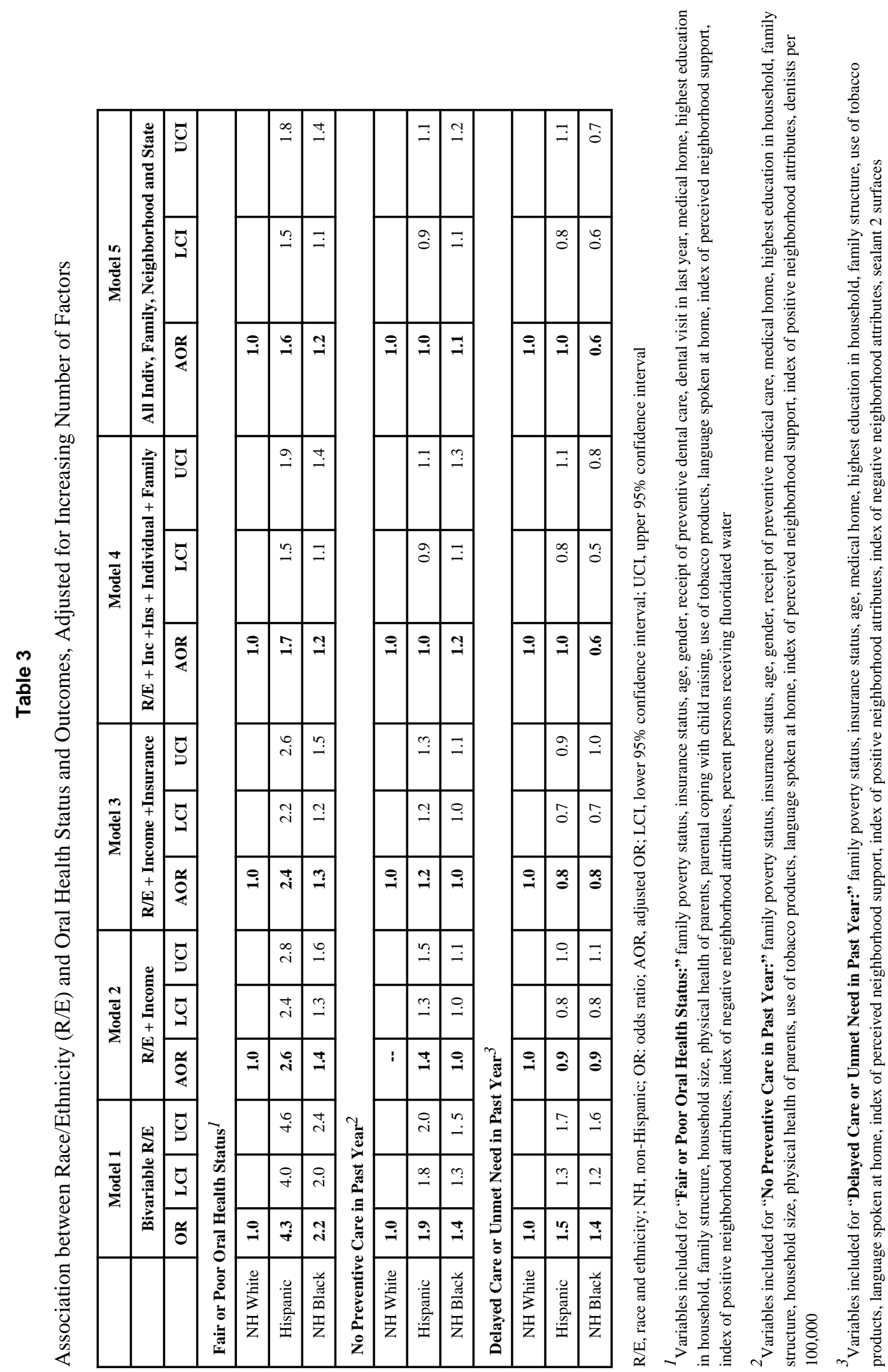

